Наталья Берницкая

Университет Сорбонна (Paris Sorbonne)

https://doi.org/10.18485/mks_knsjkk.2017.ch2

\section{КРАТКАЯ ИСТОРИЯ ПРЕПОДАВАНИЯ СЛАВЯНСКИХ ЯЗЫКОВ ВО ФРАНЦИИ}

Данная статья ставит своей целью рассказать о ключевых моментах в истории преподавания славянских языков во Франции. В своём изложении мы будем следовать принципу хронологии и совету Жана Брейара, который справедливо заметил, что, описывая историю славистики во Франции, нужно принимать во внимание два фактора: первый фактор - политический (или геополитический, или даже - геостратегический), а второй фактор - личностный, относящийся к деятельности конкретных людей [Breuillard 2010]. Объём и задачи статьи не позволят нам подробно рассказать о научной и педагогической деятельности всех французских славистов, и перечень цитируемых имён будет во многом неполным. Мы будем говорить о преподавании преимущественно с грамматических и лингвистических позиций, хотя, разумеется, невозможно изучать язык, не опираясь на культурно-исторические реалии и на литературные источники. В силу своей доминирующей роли среди славянских языков, изучаемых во Франции, ведущее место в статье будет занимать русский язык.

Ключевые слова: история, культура, славянские языки, Франция, русский язык.

\section{1. Предыстория}

Политические и экономические связи Франции со славянским миром установились довольно давно. Здесь можно вспомнить матримониальные союзы между королевскими семьями: Анну, дочь Ярослава Мудрого, которая становится супругой французского короля Генриха I в середине XI века, или брак Людовика XV с Марией Лещинской, дочерью свергнутого польского короля Станислава. Можно также вспомнить тот факт, что французский король Генрих III был также королём Польши, а Генрих IV за три недели до смерти открыл французское Консульство в Гданьске. Однако вплоть до XIX века вопрос о системном изучении славянских языков во Франции не стоял серьёзно. Одна из причин этой ситуации кроется в том, что Франция занимала весьма пре- стижное положение на мировой и европейской арене, что подразумевало широкое распространение французского языка в политических и культурных сферах других государств, в частности, в России, где интеллектуальная элита во второй половине XVIII века и в XIX веке изъяснялась по-французски подчас гораздо лучше, чем по-русски. Исключение составляет, пожалуй, только эпоха Ярослава Мудрого: в этот период Киевская Русь была значительно могущественнее, чем французское государство. В XVIII веке, несмотря на визит Петра Великого в Париж в 1717 году, и позже, несмотря на европейские амбиции Екатерины II, Россия и славянский мир оставались для Франции довольно туманным объектом. Туман несколько рассеется с приходом к власти Наполеона Бонапарта. После падения Наполеона связи Франции и России станут ещё крепче.

На этом историческом фоне изучение славянских языков во Франции было скорее случайностью, чем закономерностью и существовало лишь благодаря интересу редких энтузиастов Одним их этих энтузиастов был аббат Габриэль Жирар (Gabriel Girard), грамматист, автор первого словаря французских синонимов, переводчик с русского и старославянского при Филиппе Орлеанском, регенте Людовика XV. В том же XVIII веке, а именно в 1724 году, выходит первая грамматика русского языка, написанная на французском языке Жаном Сойе (Jean Sohier). В защиту Франции заметим, что почти полное безразличие к изучению славянских языков существовало практически во всех странах Западной Европы, за исключением Германии и Австрии. Германию можно по праву назвать колыбелью западной славистики Славянские языки преподаются в Германии, в частности, в Халле начиная с конца XVII в. На протяжении практически двух веков славистика в Западной Европе оставалась исключительно немецкой. В XIX в. Австрия становится вторым научным центром по изучению славянских языков.

\section{XIX век. Мицкевич и Коллеж де Франс}

Славянский мир официально вошёл во французскую академическую среду всего лишь 177 лет назад. В 1840 году Коллеж де Франс создаёт кафедру Славянского языка и литературы, 
предназначенную специально для изгнанного польского поэта Адама Мицкевича. Тот факт, что первая славянская кафедра была отдана поляку, не случайность. Рождение кафедры было последствием русско-польского конфликта 1830-1831 гг., после которого сочувствующая Франция приютила на своей территории примерно 10 тыс. польских эмигрантов. В середине XIX века политика Франции по отношению к России была откровенно неприязненной. Эта политика достигнет своего апогея во время Второй Империи, особенно в период Крымской войны. Не может не удивить также единственное число в названии кафедры: славянский язык, а не славянские языки. Французский славист Жак Веренк в своей статье 1985 года иронически замечает, что это единственное число красноречиво свидетельствует об уровне знаний о славянском мире в ту эпоху [Veyrenc 1985 : 246]. Однако дело, видимо, не только в недостатке знаний: многие исследователи-полонисты утверждают, что единственное число было политическим выбором, навязанным Россией [SwiatkowskaCallebat 2014 : 194]. Как бы там ни было, множественное число в названии кафедры - славянские языки и литература (langues et littératures slaves) - появится только в 1884 году.

\section{3. Основоположники славистики: период с конца Вто-} рой Империи до Первой мировой войны

В 70-е годы XIX-го столетия Франция входит в переломный период своей истории, охарактеризованный историком и филологом Клодом Дижоном (Claude Digeon) как «немецкий кризис французской мысли» [Digeon 1959]. Вслед за Седанской катастрофой, символом трагического поражения Франции во франко-прусской войне, ознаменовавшей конец Второй Империи, во франко-русских отношениях наступает потепление.

Незадолго до падения Второй Империи, в 1868 году, в Сорбонне впервые защищается диссертация по славистике, вернее, не одна, а две диссертации ${ }^{1}$. Их автор - двадцатипятилетний

${ }^{1}$ В XIX в. филологи во Франции обычно защищали одновременно две диссертации, одну на французском языке, а другую - на латыни. К началу XX в. эта традиция постепенно исчезла. учёный Луи Леже (Louis Léger). Одна из диссертаций посвящена Кириллу и Мефодию, а также принятию славянами христианства (Cyrille et Méthode, étude historique sur la conversion des Slaves au christianisme), а вторая - Нестору Летописцу (De Nestore rerum russicarum scriptore). C 1869 по 1870 г. Луи Леже преподаёт в Copбонне на добровольных началах историю южных славян, историю Богемии, грамматику русского и сербского языков. В 1876 году Леже добивается открытия кафедры русского и сербского языков при Школе Восточных языков ${ }^{2}$ и становится её главой. Преподавание русского языка в этом учебном заведении наберёт силу благодаря Полю Буайе (Paul Boyer), который останется на кафедре с 1891 по 1937 год. Близкий друг и соратник Антуана Meйе (Antoine Meillet), Поль Буайе не оставил после себя богатого научного наследия, но его педагогический дар и, выражаясь современным языком, его харизма, притягивали небывалое количество студентов. Учебник русского языка (Manuel pour l'étude de la langue russe), написанный Буайе в сотрудничестве с Николаем Сперанским в 1906 году, послужит не одному поколению французских славистов.

Франко-русский союз 1892 года, положивший конец русофобской политике Франции, был отмечен другим знаменательным событием - открытием в Лилле первой университетской кафедры русского языка и литературы, которую возглавил историк Эмиль Оман (Emile Haumant). Вторая университетская кафедра русского языка и литературы откроется в 1902 г. в Сорбонне.

Среди первых учёных, способствовавших развитию славистики в период до Первой мировой войны, назовём также Жюля Патуйе (Jules Patouillet), Андре Лиронделя (André Lirondelle), Жюля Легра (Jules Legras).

2 Эта школа, специализирующаяся на изучении восточных языков, была создана Кольбером в 1669 году в Турции под названием «Языковая школа для молодых людей». В 1700 году школа будет перенесена в Париж. Переменив несколько названий, она станет в 1971 году Национальным Институтом восточных языков и цивилизаций (Institut National des langues et civilisations orientales, INALCO). В настоящее время этот Институт является самым крупным центром изучения славянских языков во Франции, но до 1876 года в этом заведении славянские языки не преподавались. 
Отдельно следует упомянуть Антуана Мейе, чья научная аура позволит французской славистике выдвинуться на первостепенные позиции во всём мире.

\section{4. Институт славяноведения}

Идея создания Института славяноведения (Institut d'études slaves) зародилась в начале Первой мировой войны, когда политическая ситуация как никогда сблизила Францию и Россию ${ }^{3} .13$ января 1916 года в Актовом зале Сорбонны состоялось собрание, на которое Эрнест Дени, специалист по чешской истории, пригласил крупнейшего лингвиста Антуана Мейе, славистов Луи Леже, Эмиля Омана, Поля Буайе, Луи Легра, Андре Лиронделя, а также историков Луи Эйзенманна, Луи Рео, эллиниста Виктора Берара и Эдварда Бенеша, соратника Томаша Масарика, будущего первого президента Чехословацкой Республики. За этим собранием «Парижских славистов» последуют другие, а в ноябре 1919 года состоится открытие Института славяноведения в Париже, на улице Мишле, в доме номер 9, принадлежащем семье Эрнеста Дени. Институт находится в этом здании и по сей день, только теперь оно принадлежит университету Сорбонна (Université Paris-Sorbonne). 12 августа 1921 года чехословацкий Парламент принял решение пожертвовать миллион франков в помощь Институту славяноведения, а также на создание кафедры истории и цивилизации славянских народов, носящей имя Эрнеста Дени. И, наконец, 17 октября 1923 года Институт славяноведения отметил своё открытие вторично в более торжественных условиях: в присутствии Президента Франции Александра Мильерана и Президента Чехословакии Томаша Масарика.

В 1919 г. Эрнест Дени, первый Президент Института славяноведения, определил статус и цели Института славянских языков. Институт ставит своей основной целью - служить укреплению дружественных отношений между Францией и славянскими народами. Конкретные задачи Института заключаются в том, чтобы принимать студентов из славянских стран и помо-

${ }^{3}$ Сведения о создании Института почерпнуты из статьи Жака Веренка (Veyrenc 1985). гать им, координировать преподавание предметов, связанных со славянским миром, в Париже; создать читальные залы, библиотеку и способствовать выпуску специализированных изданий. Библиотека при Институте откроется в 1924 году, а в 1921 выходит первый номер Revue des études slaves, журнала, основанного Антуаном Мейе и Полем Буайе при активном содействии Андре Мазона (André Mazon). В том же 1921 году, после смерти Эрнеста Дени, Антуан Мейе становится главой Института. Его наследником станет Андре Мазон, который будет занимать эту должность с 1937 по 1959 год. В настоящее время Институтом руководит Пьер Гонно (Pierre Gonneau), профессор русской истории и цивилизации в Сорбонне.

Три года спустя после Первой мировой войны о позитивных изменениях в отношениях между Францией и славянским миром свидетельствует не только появление Института славяноведения на улице Мишле. В Сорбонне наряду с кафедрой истории носящей имя Эрнеста Дени и возглавляемой Луи Эйзенманном, действует Центр византийской истории и цивилизации, возглавляемый Шарлем Дилем (Charles Diehl), а в Практической школе высших исследований (Ecole pratique des hautes études) и в Институте политических исследований (Institut d'études politiques) ${ }^{4}$ преподаётся история и цивилизация славянских народов и византийское христианство. Три новых университетских кафедры славянских языков, литературы и истории открываются в других городах: в 1919 году в Страсбурге во главе с Андре Мазоном, в 1920 году в Дижоне во главе с Жюлем Легра и в 1921 году в Лионе во главе с Жюлем Патуйе. Что касается разнообразия славянских языков, то постепенно, кроме русского, в преподавание вводятся польский, чешский, сербо-хорватский и болгарский языки.

\section{5. Стержневое поколение}

Понятие «стержневое поколение» объединяет славистов, родившихся в конце XIX - начале XX вв. и проявивших себя в преподавательской и исследовательской работе после Второй миро-

${ }^{4}$ В то время - Свободная школа политических исследований (Ecole libre des sciences politiques). 
вой войны. Эти люди подхватили факел вслед за Дени, Мейе, Буайе и их соратниками, укрепили фундамент французской славистики, давший гарантии для её существования на долгие годы. Именно в этом «стержневом поколении», во многом благодаря влиянию Антуана Мейе, появилось несколько видных исследователей, которых можно по праву назвать лингвистами. До этого периода изучение языка рассматривалось лишь как средство доступа к литературе; Мейе являлся блестящим исключением из этого правила.

Один из самых талантливых учеников Антуана Мейе и Поля Буайе, Андре Мазон, оставил яркий след в истории французской славистики ${ }^{5}$. Мазон три года проработал лектором французского языка в Харькове (1905-1908), в 1911 году работал в Институте французского языка в Санкт-Петербурге ${ }^{6}$. В 1919 году, как мы уже говорили, Мазон возглавил кафедру в Страсбурге, а с 1923 по 1951 г. он стал преемником Луи Леже в Коллеж де Франс. В 1937 г., после смерти Антуана Мейе, Андре Мазон становится Президентом Института славяноведения.

Андре Вайан (André Vaillant) пришёл в славистику благодаря сербскому и хорватскому языкам. В 1924 г. он пишет совместно с Мейе «Грамматику сербо-хорватского языка» (Grammaire du serbo-croate). Однако всемирное признание ему принесут работы по старославянскому языку и по сравнительной грамматике славянских языков.

Люсьен Теньер (Lucien Tesnière), всемирно известный учёный в области общего языкознания, автор «Элементов структурного синтаксиса», начал свою карьеру в германистике. Но, будучи лектором в университете Любляны, он живо заинтересовался словенским языком. В 1924 году Теньер принимает заведование кафедрой русского языка в Страсбурге вслед за Мазоном, а в 1934 году публикует «Маленькую русскую грамматику» (Petite grammaire russe).

${ }^{5}$ В 2011 г. Revue détudes slaves посвятил отдельный номер Андре Мазону (Gonneau 2011).

${ }^{6}$ Институт французского языка в Санкт-Петербурге (Institut français de SaintPétersbourg) был создан в 1911 году при активном участии Поля Буайе. Первым директором этого заведения был Луи Рео.
В 1937 году после Мазона и Теньера заведование кафедрой славянских языков и литературы в Страсбурге доверено Борису Унбегауну. Унбегаун был русским эмигрантом. Он начал изучать славистику в Любляне, а затем переехал в Париж. Проработав двенадцать лет скромным библиотекарем в Институте славяноведения в Париже, Унбегаун защищает в 1935 году диссертацию по русскому языку XVI века. Эта работа сразу ставит его в один ряд с самыми видными славистами. Унбегаун будет преподавать также в Брюсселе, а свою университетскую карьеру закончит в Оксфорде

К перечисленным именам нужно добавить имена Пьера Паскаля (Pierre Pascal), Илько Боршака (Il'ko Borschak), Рауля Лабри (Raoul Labry), Анри Граппена (Henri Grappin), Антуана Мартеля (Antoine Martel), Поля Казена (Paul Cazin), Леона Болье (Léon Beaulieux), Марсель Эрар (Marcelle Ehrhard), первой французской славистки, и многих других. Эли Боршак написал первый во Франции учебник украинского языка (Lectures ukrainiennes avec grammaire, commentaire et lexique, Paris, Droz, 1946), Леон Болье в сотрудничестве со Стефаном Младеновым выпустил «Грамматику болгарского языка» (Grammaire de la langue bulgare, $1^{-о 0}$ изд. $1933,2^{-e}$ изд. - 1950, $3^{-e}$ изд. - 1965), Анри Граппен, Поль Казен и Антуан Мартель способствовали развитию полонистики. Слависты той эпохи были незаурядными личностями. Об их жизненном пути можно писать целые тома. Жизнь Пьера Паскаля, например больше похожа на приключенческий роман, чем на спокойное существование в храмах науки 8 .

Конец 30-ых годов ознаменовал тяжёлый для французской славистики период. Мюнхенское соглашение 1938 года подписывает смертный приговор молодой Чехословацкой республике и тем самым основательно подрывает деятельность Института славяноведения в Париже ${ }^{9}$. Кроме того, ничтожное количество постов в университетах приводит к застою карьерного роста, не говоря о том, что многим славистам, не имеющим постоянного

\footnotetext{
${ }^{7}$ О деятельности Унбегауна см. Keipert 2000.

${ }^{8}$ См., например, биографию Пьера Паскаля, написанную Софи Кёре (Coeuré 2014).

${ }^{9}$ По этому вопросу см. Millet 1979.
} 
места работы, трудно найти себе применение. Вторая мировая война остановила развитие славистики во Франции на несколько лет.

\section{6. После Второй мировой войны}

Благодаря своей роли в победе над фашистской Германией, а затем, в 60-е годы, своим космическим достижениям, Советский Союз притягивает к себе внимание многих стран мира, интригует и интересует как феномен. Изучение русского языка входит в моду. На этом гребне популярности русского языка славистика переживает благодатный период. Поль Буайе и Андре Мазон ратовали за введение русского языка в программу средней школы ещё до начала Второй мировой войны. В 1947 году официально открывается конкурсный набор преподавателей русского языка для средней школы ${ }^{10}$, а в 1955 объявляется конкурс преподавателей начальной школы ${ }^{11}$. Таким образом, русский язык начинает преподаваться во французской начальной и средней школе наряду с английским, немецким, итальянским и испанским языками; кафедры славянских языков создаются в разных городах Франции: 1945 г. - в Бордо, 1950 г. - в Ренне, 1953 г. - в КлермонФерране, 1955 г. - в Нанси, 1956 г. - в Экс-ан-Провансе, 1959 г. - в Пуатье, 1960 г. - в Кане, 1962 г. - в Гренобле и Тулузе, 1965 г. - в Нантерре, 1968 г. - в Руане и Венсене, 1969 г. - в Безансоне и Ницце. За двадцать лет, с 1950 по 1970 год, число изучающих русский язык в начальной, средней и высшей школе возрастает в 20 раз, достигая 20 тысяч человек

В 1967 году школьные учителя русского языка создают «Общество преподавателей русского языка» (Société des professeurs

\footnotetext{
${ }^{10}$ Эта конкурсная система набора, носящая название Agrégation - особенность французской образовательной системы. Посты во французской школе контролируются Министерством образования. Чтобы претендовать на постоянное место учителя в средней школе, нужно, получив университетский диплом, пройти серию устных и письменных экзаменов по выбранной специальности. Конкурс Agrégation устраивается ежегодно, количество постов в школе строго нормировано, поэтому посты распределяются между кандидатами, набравшими наибольшее количество баллов,

11 Этот конкурс называется CAPES. Он устроен примерно, как Agrégation, но на-
} целен на преподавание в начальной школе. de russe), переименованное в 1991 г. во «Французскую ассоциацию русистов» (Association française des russisants). При ассоциации издаётся журнал La Revue Russe.

В научном плане хотелось бы упомянуть о двух видных лингвистах из Экс-ан-Прованса о Поле Гарде (Paul Garde) и о Маргерит Гиро-Вебер (Marguerite Guiraud-Weber), начавших свою карьеру в 60-70-ые годы, а также об их более молодом парижском коллеге Жаке Фейе (Jack Feuillet). Поль Гард является автором незаменимой для французских славистов книги «Грамматика русского языка. Фонология и морфология» (GardeP., Grammaire russe. Phonologie. Morphologie, Institut d'études slaves, (1 $1^{\text {-о }}$ изд. - 1980, $2^{\text {-ое } и з д . ~-~ 1998, ~ 3-е ~ и з д . ~-~ 2016), ~ и м ~ н а п и с а н ы ~ в а ж н ы е ~ и с-~}$ следования по ударению (Garde P., L'accent, $1^{-е}$ изд. - 1968, Presses universitaires de France, $2^{-е}$ изд. - 2013 ${ }^{12}$ ). Этот учёный посвятил также несколько книг и статей языковой и политической ситуации в бывшей Югославии (Garde P., Vie et mort de la Yougoslavie, Paris, Fayard, 2000). Маргерит Гиро-Вебер внесла большой вклад в изучение глагольного вида ${ }^{13}$. Жак Фейе, профессор болгарского языка в Институте восточных языков и цивилизаций, написал ряд важных работ по болгарскому языку и по сопоставлению балканских языков (Feuillet J., Linguistique comparée des langues balkaniques, Paris, Institut d'études slaves, 2012).

\section{7. На стыке XX и XXI веков}

Распад СССР в 1991 г. привёл к глобальной геополитической перестройке: биполярный мир, в котором противостояли две сверхдержавы, СССР и США, превратился в однополярный мир при явном господстве США. В этот переломный период на стыке XX и XXI веков преподавание русского и других славянских языков снова переживает спад. По подсчётам «Французской ассоциации русистов» число изучающих русский язык в начальной и средней школе в период с 1988 по 2002 год снизилось вдвое, в 1988 году 12 Эта книга была переведена на русский язык: Гард, П. Ударение. Санкт-Петербург: Филологический факультет СпбГУ, 2015.

13 Со списком работ Маргерит Гиро-Вебер можно ознакомиться в сборнике «Questions de linguistiques slave. Etudes offertes à Marguerite Guiraud-Weber», Publications de l'Université de Provence, 2008. 
насчитывалось 26763 ученика, а в 2002 - 13300 учеников (Comte 2006), количество преподавателей также сократилось. В университетах ситуация была, пожалуй, менее критическая, но этому во многом способствовал приток студентов из бывших республик Советского Союза и социалистического блока.

\section{8. Славистика сегодня}

В настоящее время можно отметить две тенденции по отношению к славянским языкам во Франции (и в Европе): 1) все славянские языки, кроме русского, с трудом выживают в образовательной системе; 2) ситуация с русским языком нестабильна; на общем фоне падения интереса к русскому языку наблюдаются время от времени вспышки энтузиазма. Обе эти тенденции, конечно же, связаны с политической и экономической ситуацией во Франции и во всём мире. Одним из последствий распада СССР является переоценка ценностей в современном обществе. Противостояние двух блоков - СССР и США - предполагало также противостояние двух идеологий. Сегодня, безусловно, можно при желании найти множество идеологий, но преобладает всётаки одна единственная идеология - либеральная, что отражается также и на образовании, в частности, на выборе иностранного языка в школе. Если раньше в школах предлагалось на выбор несколько иностранных языков, то сегодня школы практически навязывают обязательное изучение английского в ущерб другим языкам. Только испанскому языку удаётся конкурировать с английским. Такое положение обусловлено финансовой политикой французского государства, в целом направленной на урезание бюджета. Количества классов сокращается, а количество учащихся в группе увеличивается. Например, если на уроке иностранного языка присутствует меньше семи учеников, предмет убирается из программы. Таким образом, количество преподавательских постов сокращается, а редкие языки исчезают из начальной, средней и высшей школы. Данная ситуация характерна и для средней, и для высшей школы. В результате такой политики университет Сорбонны, например, несколько лет назад был вынужден отказаться от преподавания украинского и болгарского языков.
Русский язык находится, конечно, в более выигрышном положении, чем остальные славянские языки, хотя слабая экономика и несколько померкшая слава России в научных и технических достижениях не способствуют пробуждению энтузиазма. К тому же в последнее время во Франции преобладает антироссийская политика, и образ России в средствах массовой информации оставляет желать лучшего. Хотя, как замечает Людмила Афанасьева [Afanas'yeva 2012], негативные стереотипы о России скорее распространены среди среднестатистических французов, а интеллектуальная и политическая элита нюансирует свои взгляды и относится к России скорее с симпатией. Положение русского языка в начальной и средней школе довольно шаткое, но в университете ему пока удаётся сохранять стабильные позиции. В последнее время отмечается даже лёгкая тенденция к увеличению количества студентов. Этот рост происходит, как мы уже отмечали, во многом за счёт студентов-выходцев из республик бывшего Советского Союза и из бывшего социалистического блока, а также благодаря занятиям, предназначенным исключительно для начинающих: такие специализированные программы, предусматривающие изучение русского как иностранного с нуля, введены практически во всех вузах Франции.

В настоящее время трудно найти точные цифры о количестве студентов, изучающих славянские языки. Секция славянских языков при Национальном Совете университетов (Le Conseil National des Universités $)^{14}$ как раз сейчас проводит подсчёты студентов, и можно надеяться, что через несколько месяцев в официальных источниках появятся точные данные обо всех университетах Франции. Приведём пока данные 2005 года, предложенные Французской ассоциацией русистов: в 2005 г. русский язык изучался в 25 университетах Франции, на 200 преподавателей всех рангов и категорий приходилось примерно 3000 студентов различных уровней [Comte 2006].

\footnotetext{
${ }^{14}$ Функции Национального Совета университетов можно примерно сравнить с российской Высшей Аттестационной Комиссией (ВАК).
} 


\section{9. Заключение}

Несмотря на все трудности, о которых мы упомянули, наши выводы о ситуации и перспективах изучения славянских языков во Франции не будут пессимистичными. Правительства славянских стран, Ассоциация французских славистов, Институт славяноведения, различные культурные центры и просто отдельные преподаватели и энтузиасты делают всё, чтобы славянские языки не только не исчезли из интеллектуального пространства Франции, а, наоборот, набирали силу и процветали.

2010 год был объявлен во Франции годом России, а 2012 год - годом русского языка и литературы. В связи с этим во Франции проводились книжные ярмарки, выставки, чтения, концерты и т. д., посвящённые России. В 2009 г. открылись сразу два лицея, специализирующихся по русскому языку, в Страсбурге и Ницце. 19 октября 2016 года состоялось торжественное открытие Русского духовно-культурного центра в Париже. Территория центра является частью посольства РФ во Франции. Центр организует занятия по русскому и церковнославянскому языкам и проводит различные научные и культурные мероприятия.

Многие французские университеты подписали договоры о сотрудничестве с университетами России, Сербии, Польши, Болгарии, Чехии. Эти славянские страны продолжают направлять во французские университеты своих лекторов.

Наука также не стоит на месте, и мы можем отметить множество интересных событий и публикаций, например, «Грамматику боснийского, хорватского, черногорского и сербского языков» Поля-Луи Тома и Владимира Осипова (Thomas P.-L., Ossipov V., Grammaire du bosniaque, croate, monténégrin, serbe, Institut d'études slaves, 2012); «Синтаксис русского языка» Робера Руде (Roudet R., Grammaire russe. Syntaxe, Institut d'études slaves, 2016), первую во Франции серьёзную монографию по синтаксису современного русского языка, написанную как продолжение «Фонологии и морфологии» Поля Гарда; «Историю русского языка от истоков до XVIII в.» Жана Брейара и Стефана Вьеляра (Breuillard J., Viellard S., Histoire de la langue russe des origines au XVIII ${ }^{e}$ siècle, Paris, Institut d'études slaves, 2015), «Старославянский язык» Клер Ле Февр (Le
Feuvre C., Le vieux slave, Peeters, Leuven-Paris, 2009). Французские слависты принимают активное участие в различных конференциях и семинарах, можно, в частности, подчеркнуть заметную роль французской делегации на Международных Съездах славистов.

Примечателен тот факт, что с самого начала своего существования французская славистика привлекала к себе учёных, которые не ограничивались изучением только славянских языков, но являлись в то же время признанными специалистами по другим языкам. Один из основателей французской славистики Антуан Мейе является всемирноизвестным индоевропеистом, Люсьен Теньер, пришедший в славистику из германистики, получил широкое признание в области общего языкознания, Жак Фейе - автор нескольких книг по германистике, основной специальностью Клер Ле Февр является древнегреческий язык... Таким образом, сегодня можно по праву говорить о французской славистике как о солидной сложившейся традиции, в которой научная мысль и педагогический опыт передаются из поколения в поколение, но которая в то же время открывает свои двери новым людям и свежим идеям.

\section{БИБЛИОГРАФИЯ}

Coeuré, S. La Russie entre christianisme et communism. Paris: éd. Noir sur Blanc, 2014.

Digeon, C. La crise allemande de la pensée française (1870-1914). Paris: Presses universitaires de France, 1959.

Dominois, F. «Louis Eisenmann », Revue des études slaves, volume 17, numéro 3 (1973): pp. 240-244

Fichelle, A. « Origine et développement de l'Institut d'études slaves (1919-1949)», Revue des études slaves, tome 27 (1951): pp. 91-103.

Girardet, R. « Digeon Claude. - La crise allemande de la pensée française (1870-1914)», Revue française de science politique, volume 13, numéro 1 (1963): pp. 202-203

Gonneau, P. et al. « La slavistique française, 1980-2000.», in: Bercoff G. B. Gonneau P. Miklas H. (eds.). Contribution à l'histoire de la slavistique dans les pays non slaves / Beiträge zur Geschichte der Slawistik in nichtslawischen 
Ländern / К истории славистики в неславянских странах. Wien: Verlag der Österreichischen Akademie der Wissenschaften (Schriften der Balkankommission, t. 46), Centre d'études slaves (Travaux publiés par l'Institut d'études slaves, t. XLVI), 2005.

Gonneau, P. „André Mazon (1881-1967) et les études slaves”, Revue des études slaves, tome 82, fascicule 1 (2011).

Keipert H. «Boris Unbegaun's Work in Contemporary Slavonic Philologie», The Slavonic and East European Review, 78 (2000): pp. 601-611.

Mazon, A. «Le patrimoine commun des études slaves, leçon d'ouverture du cours de langues et littératures slaves au Collège de France», Revue des études slaves, volume 4, numéro 1 (1924): pp. 113-132.

Mazon, A. Les études slaves. Paris: Larousse, 1933.

Mazon, A. «L'abbé Gabriel Girard, grammairien et russisant», Revue des études slaves, volume 35, numéro 1 (1958): pp. 15-56.

Millet, Y. «L'Institut d'études slaves et la Tchécoslovaquie », in Revue des études slaves, volume 52, numéro 1 (1979): pp. 21-31

Siatkowska-Callebat, K. «L'histoire de l'enseignement du polonais en France», in: Enseigner et apprendre le polonais langue étrangère (sous la dir. de L. Kolankiewicz et A. Zieniewicz). Centre de civilisation polonaise (Université Paris-Sorbonne) \& Polonicum, Centre de langue et de culture polonaises pour les étrangers (Université de Varsovie), 2014.

Veyrenc J. «Histoire de la slavistique française», in: Hamm. J. Wytrzens G. (ed.). Beiträge zur Geschichte der Slawistik in nichtslawischen Ländern. Wien: Verlag der Österreichischen Akademie der Wissenschaften (Schriften der Balkankommission, Linguistische Abteilung, t. XXX), 1985.

\section{ЭЛЕКТРОННЫЕ ССЫЛКИ}

Напомним, что все номера Revue des études slaves до 2012 года находятся в электронном варианте на сайте Persée - http://www.persee. $\mathrm{fr} /$ collection/slave

Afanas'yeva L. (2012), L'enseignement du russe en France dans le système éducatif public (lycées) : états des lieux et perspectives, Thèse de doctorat, Université Paul Valéry Montpellier III. - https://tel.archives-ouvertes.fr/tel00824551/document

Boyer P., Mazon A. (1926), Les relations scientifiques entre la France et la Russie. - http://www.etudes-slaves.paris-sorbonne.fr/spip. php?rubrique 277
Breuillard J. (2010), Bref historique des études slaves en France. http://etudesslaves.edel.univ-poitiers.fr/index.php?id=100

Comte Ph. (2006), Bulletin de l'Association Française des Russisants. http://www.aplv-languesmodernes.org/spip.php?article204

\section{L'HISTOIRE DE L'ENSEIGNEMENT DES LANGUES SLAVES EN FRANCE}

L'exposé est consacré à l'histoire de l'enseignement des langues slaves en France, à partir du XIXème siècle à nos jours. Il est intéressant de décrire cette histoire en aordant des question de culture et d'histoire. 